\title{
Mandibular Reconstruction with Autogenous Graft After Surgical Treatment of Cemento-Ossifying Fibroma: a Case Report and Literature Review
}

\author{
Rodrigo Lemos Alves 1, Jonas Nogueira Ferreira Maciel Gusmão 1*, Bruno Frota Amora Silva 1, Rodrigo \\ Cristhian Avelino Bezerra 1, Eliardo Silveira Santos 1, Antonio Mont'Alverne Lopes Filho 1 \\ ${ }^{1}$ Department of Oral and Maxillofacial Surgery, Hospital Geral de Fortaleza, HGF, Fortaleza, Brazil. \\ *Corresponding author: Jonas Nogueira Ferreira Maciel Gusmão. Ávila Goularte, n900 - Papicu. Zip Code: 60150- \\ 160 - Ceará, CE, Brazil. Phone: +55 (85)9 8141-6401. E-mail: jonasnferreira@yahoo.com.br
}

Research Ethics Committee Approval (if necessary): Approved by the Hospital Geral de Fortaleza Ethics Committee (\#685.967).

Received on: Mar 25, 2021. Accepted on: Mar 26, 2021. Available online: Apr 1, 2021.

\section{Abstract}

Fibro-bone lesions (LFO) are defined as a group of lesions characterized by the replacement of normal bone tissue with fibrous connective tissue, of variable cellularity, permeated by a variable amount of mineralized material, whose microscopic appearance may resemble bone, cement or a mixture of both. Among the injuries that make up this group, we can mention: fibrous dysplasia, ossifying fibroma, bone dysplasia and cemento-bone dysplasia. In this case report, we presented a mandibular reconstruction with free autogenous graft from the iliac crest, with the use of stereolithography prototyping, after the surgical treatment of a cemento-ossifying fibroma, as well as to describe the clinical, epidemiological, radiographic characteristics, and histological, the differential diagnosis and the form of treatment of the referred pathology.

Keywords: Cemento-Ossifying Fibroma; Autogenous Graft; Surgery; Treatment.

\section{Introduction}

Fibro-bone lesions (LFO) are defined as a group of lesions characterized by the replacement of normal bone tissue with fibrous connective tissue, of variable cellularity, permeated by a variable amount of mineralized material, whose microscopic appearance may resemble bone, cement or a mixture of both. Among the injuries that make up this group, we can mention: fibrous dysplasia, ossifying fibroma, bone dysplasia and cemento-bone dysplasia [1].

According to Santos and colleagues [1], among the fibro-osseous 
lesions, in a sample of 112 cases, cemento-ossifying fibroma (CFO) was the most frequent.

CFO is a rare, benign tumor that affects the craniofacial region, usually in the third and fourth decades of life with a predilection for the mandible. The female sex is more affected in a 5: 1 ratio. However, its controversial etiology is believed to originate from the periodontal membrane, which contains blast cells capable of forming bone tissue, cementum and fibrous tissue [2].

CFO is asymptomatic in most cases, and is discovered in a routine radiographic examination or when it causes aesthetic (asymmetry) and / or functional (malocclusion) changes. Eventually, CFO is associated with divergence and root resorption of the teeth associated with the lesion [3].

Radiographic examination shows a radiolucent, unilocular, well-defined area, with sclerotic borders, with or without radiopaque foci inside, varying according to the presence of calcified material [3]. Histopathological examination shows connective tissue rich in fibroblasts interspersed with blood vessels, with the presence of calcified material compatible with bone tissue or cementum. The diagnosis is established based on clinical, radiographic and histopathological data. It is of fundamental importance to correlate these data to establish the diagnosis, since the histopathological reading of fibro-osseous lesions is very similar [1-3].

The treatment consists of surgical removal, through enucleation, where, in most cases, the lesion is easily detached from the healthy bone. In cases of extensive lesions, a more radical treatment is indicated, resection, and the reconstruction procedure with grafts, plates and screws may be necessary. The ablative surgery resulting from the treatment of tumors results in a defect in the mandibular bone continuity. The resection of a mandibular segment, without adequate reconstruction, produces severe aesthetic (asymmetry) and functional (difficulty in chewing, swallowing) sequelae leading to a loss of quality of life [1-3].

The reconstruction of mandibular defects after tumor resections is a challenge for the surgeon. There are several techniques for mandibular reconstruction and countless materials available on the market, each with its advantages and disadvantages, as well as its clinical applicability, and the surgeon, together with the patient, must establish the most appropriate for the situation in question [1-3].

The most common form of treatment, when it is necessary to reconstruct the mandible, is the one that recommends an autogenous bone graft associated with a titanium reconstruction plate, promoting the restoration of continuity of the mandible, with simultaneous three- 
dimensional stability of the fragments, allowing that graft incorporation can occur with immediate function and without the need for maxillomandibular block. The iliac bone is the donor area most frequently used in this type of reconstruction, in view of the amount of tissue available. The prognosis of OCF is good and recurrence is rare [1-3].

In this context, the objective of this case report was to present a mandibular reconstruction with free autogenous graft from the iliac crest, with the use of stereolithography prototyping, after the surgical treatment of a cemento-ossifying fibroma, as well as to describe the clinical, epidemiological, radiographic characteristics, and histological, the differential diagnosis and the form of treatment of the referred pathology.

\section{Case report}

Female patient, 34 years old, feoderma, was assisted by the Dentistry Sector of the Buccomaxillofacial Surgery and Traumatology Service of the Hospital Geral de Fortaleza for evaluation, complaining of morphological changes in the mental region.

In the anamnesis, the patient denied underlying diseases, allergies and / or chemical dependence. On extra-oral examination, the patient presented facial asymmetry associated with an increase in mandibular volume on the right in a frontal view (Figure 1A). Intra-oral examination, absences of teeth $18,14,24,38,37,36,45,46,47,48$ and root debris corresponding to elements 26 and 27 were observed.

Radiographic examination showed the presence of a radiolucent, unilocular, well circumscribed area, with areas suggestive of calcification in the region of the mandibular symphysis, associated with the apexes of the teeth $34,33,32,31,41,42,43$ and 44, without causing root resorption (Figure 1B). The sensitivity test was positive for such dental elements.

The computed tomography (CT) exam revealed a tumor mass, sometimes hyperdense, sometimes hypodense, with expansion of the buccal / lingual and basilar corticals, showing hyperdense areas inside (Figures $1 \mathrm{C}$ to 1E).

The patient was submitted to an incisional biopsy by intraoral access, under local anesthesia, and the specimen was sent to the Histopathology Laboratory of the University of Fortaleza (UNIFOR) with the diagnostic hypothesis of Fibro-bone Injury / Pindborg's Tumor.

According to histopathological diagnosis, the presence of fragments of connective tissue was observed, showing an intense proliferation of spindle and oval cells interspersed by numerous deposits of basophilic mineralized globules, with the conclusion that it was a benign fibro- 
bone lesion suggestive of Central hematological examination

was Cemento-Ossifying Fibroma. The patient was referred for tumor requested, which was within the normal termination surgery. Preoperative
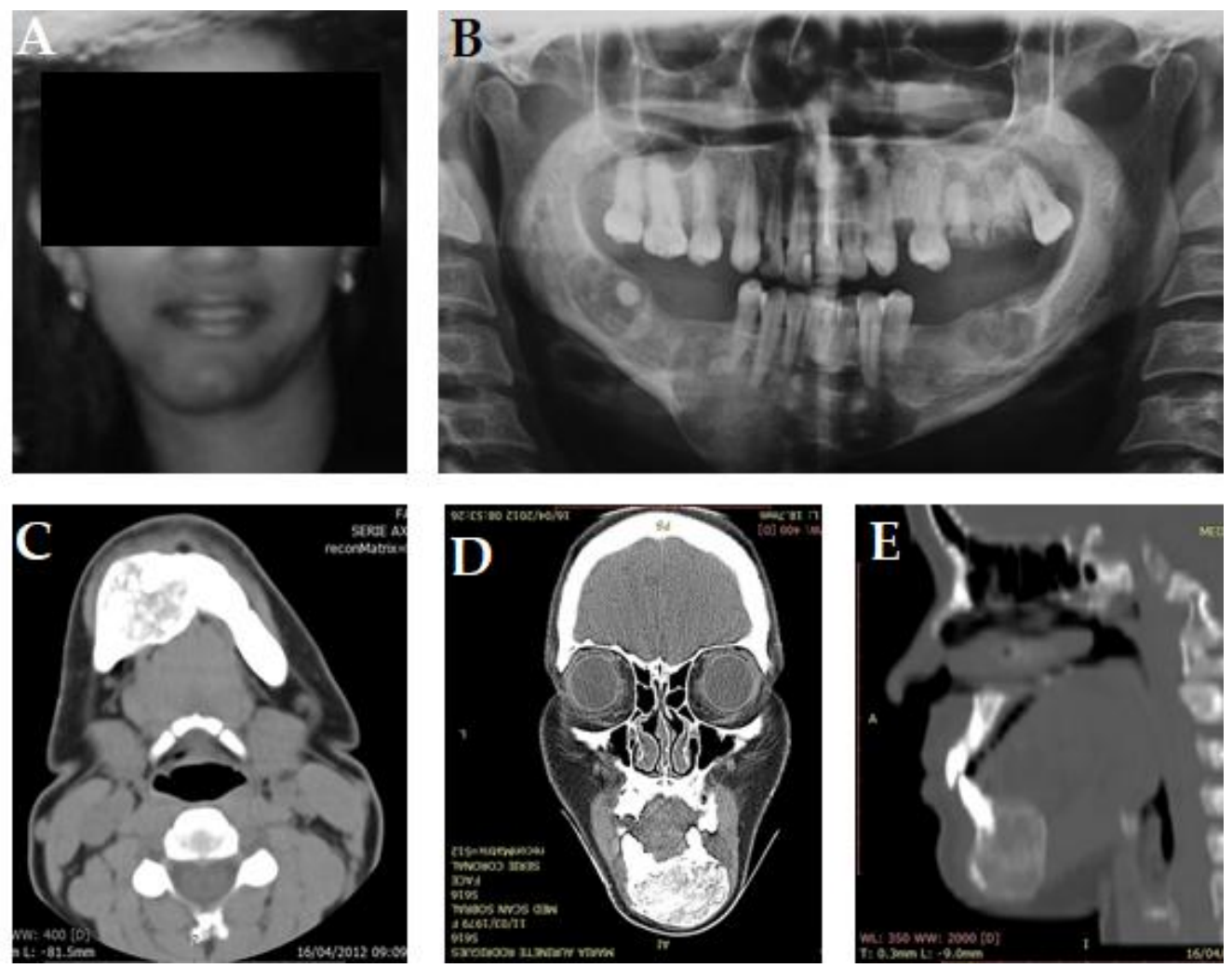

Figure 1. A. Frontal view of the patient with increased volume in the mental region. B. Panoramic radiograph showing radiolucent, unilocular lesion, with an area suggestive of calcifications inside the region of the symphysis and right mandibular parasymphysis without root resorption of the associated teeth. C. Axial computed tomography of the face showing hypodense and hyperdense areas with expansion of the buccal and lingual cortices. D. Coronal computed tomography of the face showing the expansion of the basilar cortex of the mandible. E. Sagittal computed tomography of the face showing the intimate relationship of the lesion with the remaining teeth.

The patient underwent curettage with peripheral ostectomy, under general anesthesia, through total submandibular access (enveloped flap).

In view of the easy detachment of the lesion from the healthy bone remainder, it was possible to maintain the alveolar ridge with the teeth associated with the lesion, and a $2.4 \mathrm{~mm}$ System plate with 3 bicortical screws on each side was installed, returning the mandibular contour and serving as reinforcement for prevention of a pathological fracture. The patient evolved uneventfully and was 
Mandibular Reconstruction with Autogenous Graft in Cemento-Ossifying Fibroma

discharged four days after the surgery (Figures 2A to 2D).

The patient followed clinical and radiographic follow-up at that service for 1 year and 6 months, with no signs
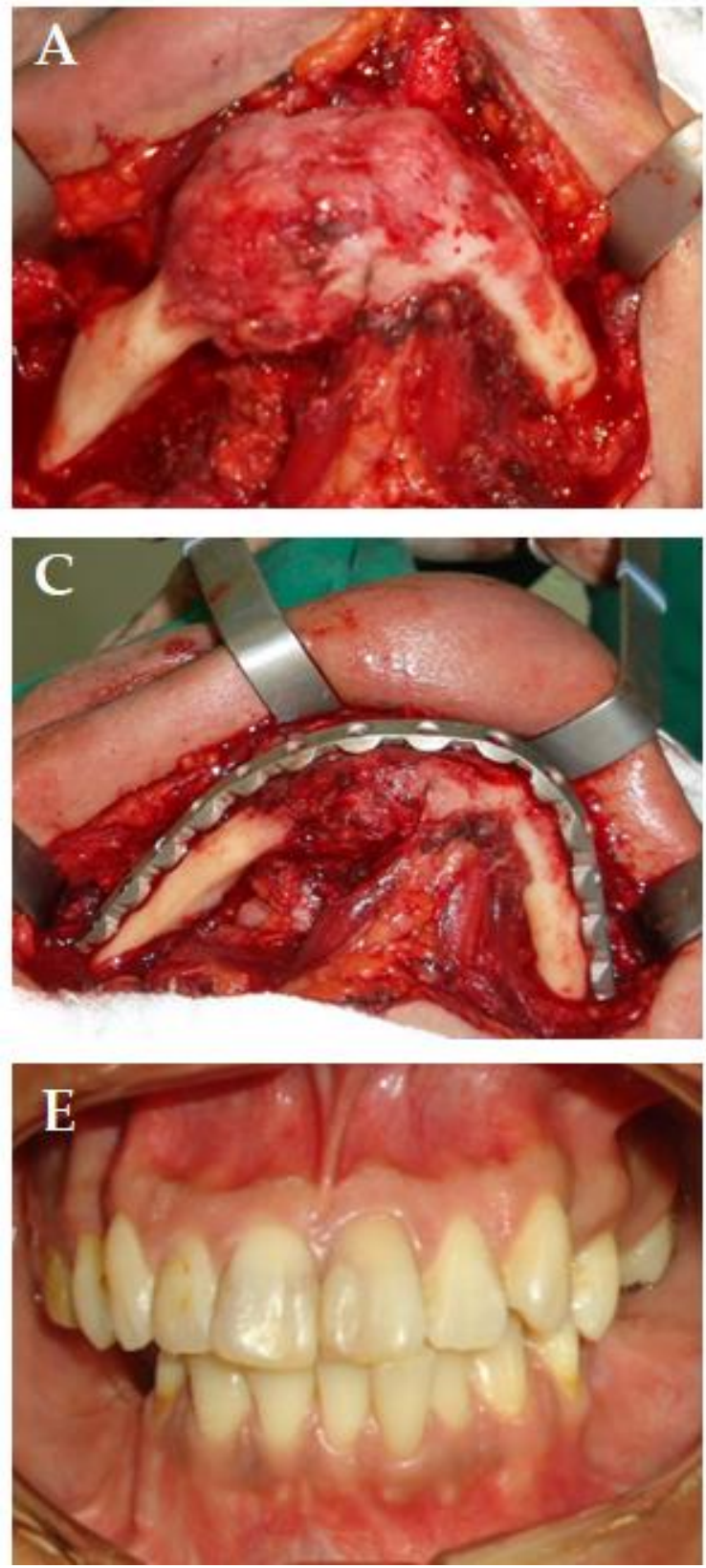

of recurrence, or any type of local infectious complication, with a hypertrophic scar in the cervical region (Figures 2E and 2F).
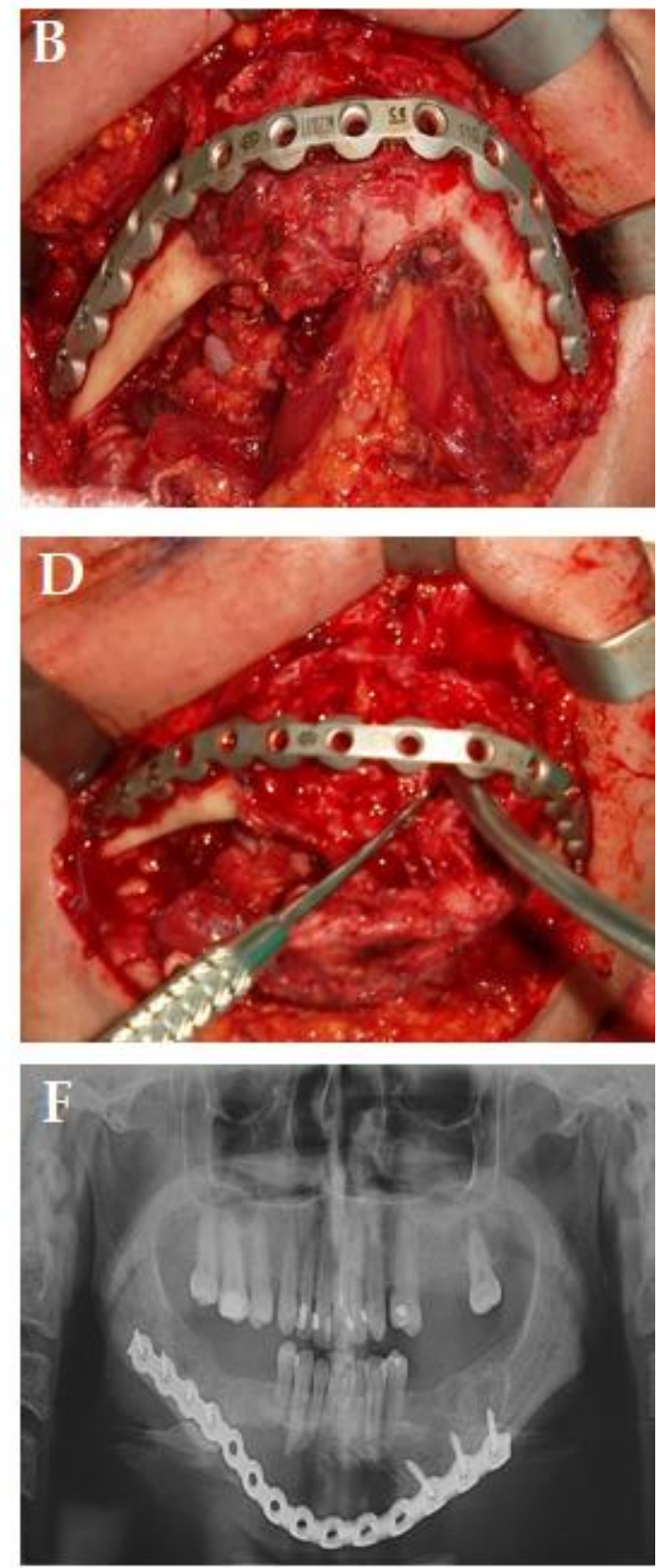

Figure 2. A. Exposure of the entire lesion after total submandibular access. B. Wear of the anterior portion of the lesion restoring the contour of the buccal cortex of the mandible for the installation of the reconstruction plate prior to the curettage and peripheral ostectomy. C. Submental view after wear of the anterior portion of the tumor and the installation of the reconstruction plate preserving the mandibular contour. D. Tumor curettage. E. Stable occlusion in the 10th month after surgical treatment. F. 
Panoramic postoperative radiograph of the 10-month control with no signs of recurrence of the lesion.

After this period, the hospital team scheduled mandibular reconstruction. A computed tomography scan of the face with frontal (Figure $3 \mathrm{~A}$ ) and coronal sections (Figure 3B) was requested, according to the protocol for the acquisition of medical images established by the Renato Archer Information Technology Center, through which a full-size prototype (Selective Laser Sintering) was obtained, without charge, planning of mandibular reconstruction with iliac crest grafting. After analyzing the tomographic sections, it was found that there was a type " $\mathrm{C}$ " defect according to the classification by Jewer et al (1989).

The area to be reconstructed was waxed and then, after its removal from the prototype, the waxed block was printed in alginate in order to obtain a mold of the bone block that will be necessary to reconstruct the operated area (Figure 3C and 3D).

When molding, self-curing acrylic resin was poured, to obtain an apparatus that reproduced the actual size of the bone block necessary to reconstruct the mandible and guide the surgeon on the size of the bone block that would be necessary (Figure 3E and $3 \mathrm{~F})$.

The mandibular reconstruction surgery took place under general anesthesia, in conjunction with the Traumatology and Orthopedics service of the Hospital Geral de Fortaleza. The recommended access to approach the iliac crest was a $6 \mathrm{~cm}$ long straight incision over the anterosuperior iliac crest, followed by blunt divulsion of the planes until the internal and external iliac crest surface was exposed.

The tricortical three-dimensional bone block, measuring $4 \times 2.5 \times 1 \mathrm{~cm}$, was removed with the use of chisels and hammer. The bone block removed was inserted into the pre-existing bone defect and fixed with reconstruction plate and bicortical screws. Then, curettage of the medullary bone of the iliac crest was performed, which was placed in the gaps between the graft and the recipient area. After reviewing hemostasis and bone regularization at the donor site, suturing was performed using tissue planes and the application of a dressing.

The recommended access for the exposure of the recipient area was the total submandibular access, taking advantage of the pre-existing cutaneous scar, with the removal of the hypertrophic scar, divulsion by planes, followed by local curettage to remove scar tissue interposed in the recipient bed (Figure $4 \mathrm{~A}$ to $4 \mathrm{I})$. 

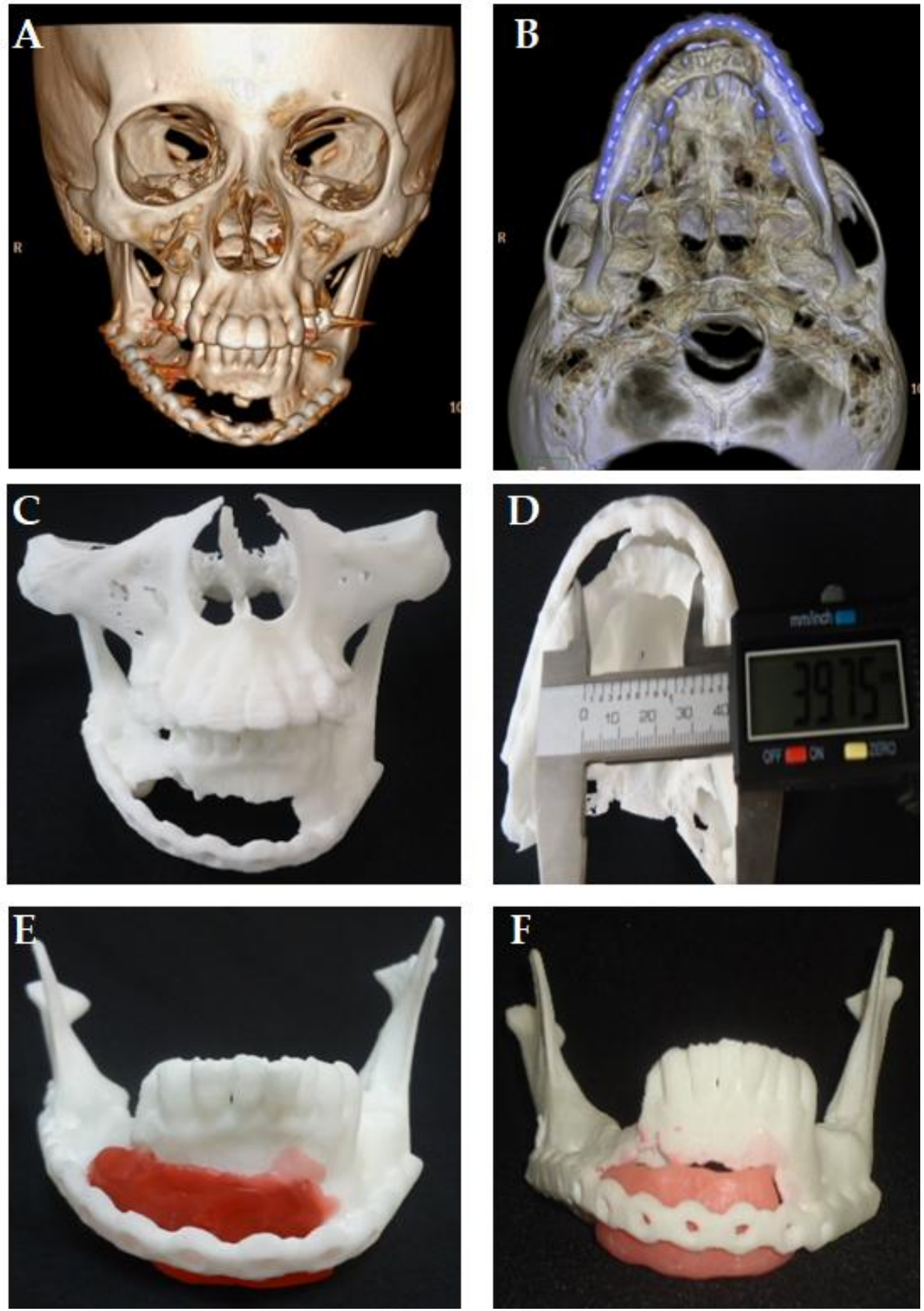

Figure 3. A. Three-dimensional reconstruction of computed tomography of the face in a frontal view with the defect of the mandibular segment in the anterior region. B. Threedimensional reconstruction of the computed tomography of the face in a lower view showing the extent of the mandibular defect. C. Stereolithographic model of the disarticulated jaws obtained for planning mandibular reconstruction. D. Measurement of the actual size of the bone segment to be reconstructed (approximately $4 \mathrm{~cm}$ ). E. Waxing of the bone defect in the stereolithographic model. F. Acrilization of the bone block mold necessary for the reconstruction of the segment. 
Numerous perforations were made in the mandibular stumps, under abundant irrigation with $0.9 \%$ saline, to promote neovascularization in the area. In the course of the surgery, the team found it prudent to replace the reconstruction plate, with a smaller profile, returning greater symmetry to the mandibular contour and making the soft tissue covering more passive over the grafted area (Figure $4 \mathrm{~A}$ to $4 \mathrm{I}$ ). Subsequently, the sutures were made using planes and the application of a compressive dressing. The immediate postoperative diet remained zero.
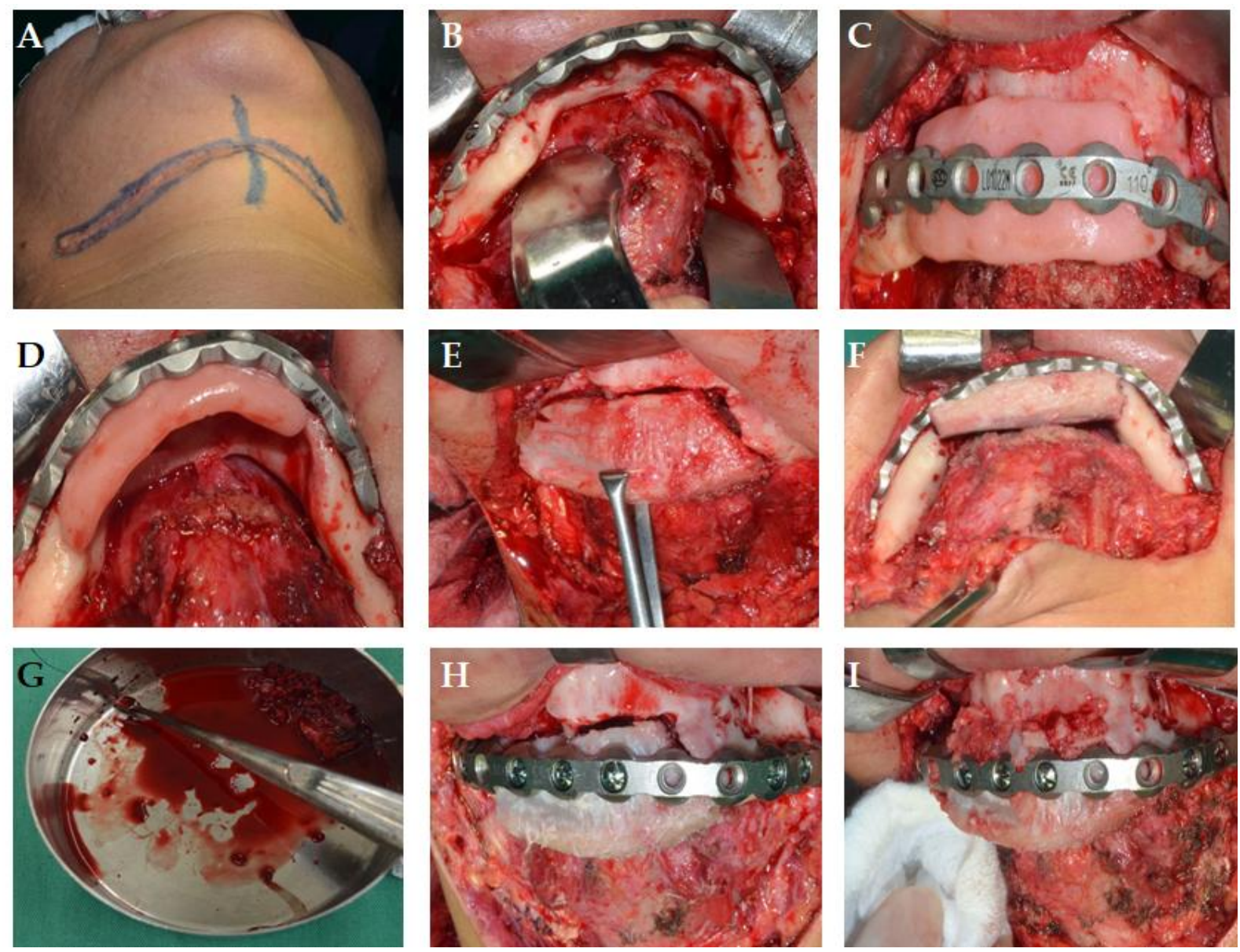

Figure 4. A. Demarcation of the incision in the second surgical procedure. B. Receptor area after removal of interposed scar / fibrous tissue. C. Front view of the "template" in the receiving area to assess the fidelity of the stereolithographic model. D. Bottom view of the "template" positioned in the receiving area. E. Bone block positioned in the receiving area after removal of the fixation material. F. Installation of the reconstruction plate and fixation of the graft with bicortical screws. G. Medullary bone with crest marrow aspirate obtained through curettage after removal of the bony block from the iliac crest. H. Presence of gaps at the interface of the grafted bone block and the 
recipient area. I. Filling of the gaps at the graft interface versus the recipient area with particulate bone from the iliac crest.

On the first postoperative day, edema compatible with the surgical procedure, physiological activities present, facial movements preserved, absence of suture dehiscence, absence of signs of infection were observed, cleaning and dressing change were performed and prescribed a cold liquid diet. She was induced to walk right after the first 24 hours after the surgery, where a change in gait was observed even with the assistance of the companion.

The patient was discharged three days after the surgery, with a slight change in gait. The patient was medicated orally with: Amoxicillin $\AA$, $500 \mathrm{mg}$ with intervals of 08 (eight) hours between taking, during 07 days; Nimesulide ${ }^{\circledR}, 100 \mathrm{mg}$ with intervals of 12 (twelve) hours between taking, during 04 days and Dipirona ${ }^{\circledR}, 500 \mathrm{mg}$ with intervals of 06 (six) hours between taking in case of pain. In addition, the patient received postoperative guidance on the need to perform warm compresses in the operated area and notions of hygiene of the surgical wound. The patient progressed satisfactorily, with no graft exposure or local infection and a complete repair of the surgical wound.

The patient was monitored by 7 , $15,30,60,90,120,150$ and 180 days after the operation, showing good recovery of the operated regions and absence of limitation or discomfort during ambulation. The complete incorporation of the graft was diagnosed by means of clinical and imaging tests (Figures 5A to 5G) after six months. The patient continues to be followed up on an outpatient basis, with 240 days postoperatively, with no local complications and referred for oral rehabilitation.

Table 1. Reported cases of patients with Cemento-Ossifying Fibroma.

\begin{tabular}{|c|c|c|c|}
\hline Author, year & $\begin{array}{l}\text { Imber of } \\
\text { cases }\end{array}$ & Description & References \\
\hline Alsharif et al., 2009 & 127 & Description of Benign Fibro-Osseous Lesions & [7] \\
\hline Santos et al., 2007 & 112 & Report of benign fibro-osseous lesions of the jaws & [1] \\
\hline Triantafillidou et al., 2012 & 14 & Report of Ossifying fibroma of the jaws & [4] \\
\hline Bist et al., 2011 & 1 & $\begin{array}{l}\text { Report of Juvenile aggressive cemento-ossifying } \\
\text { fibroma }\end{array}$ & [5] \\
\hline Castro et al., 2007 & 1 & Report of central cemento-ossifying fibroma & [6] \\
\hline
\end{tabular}

Legend: Studies obtained by PUBMED. 

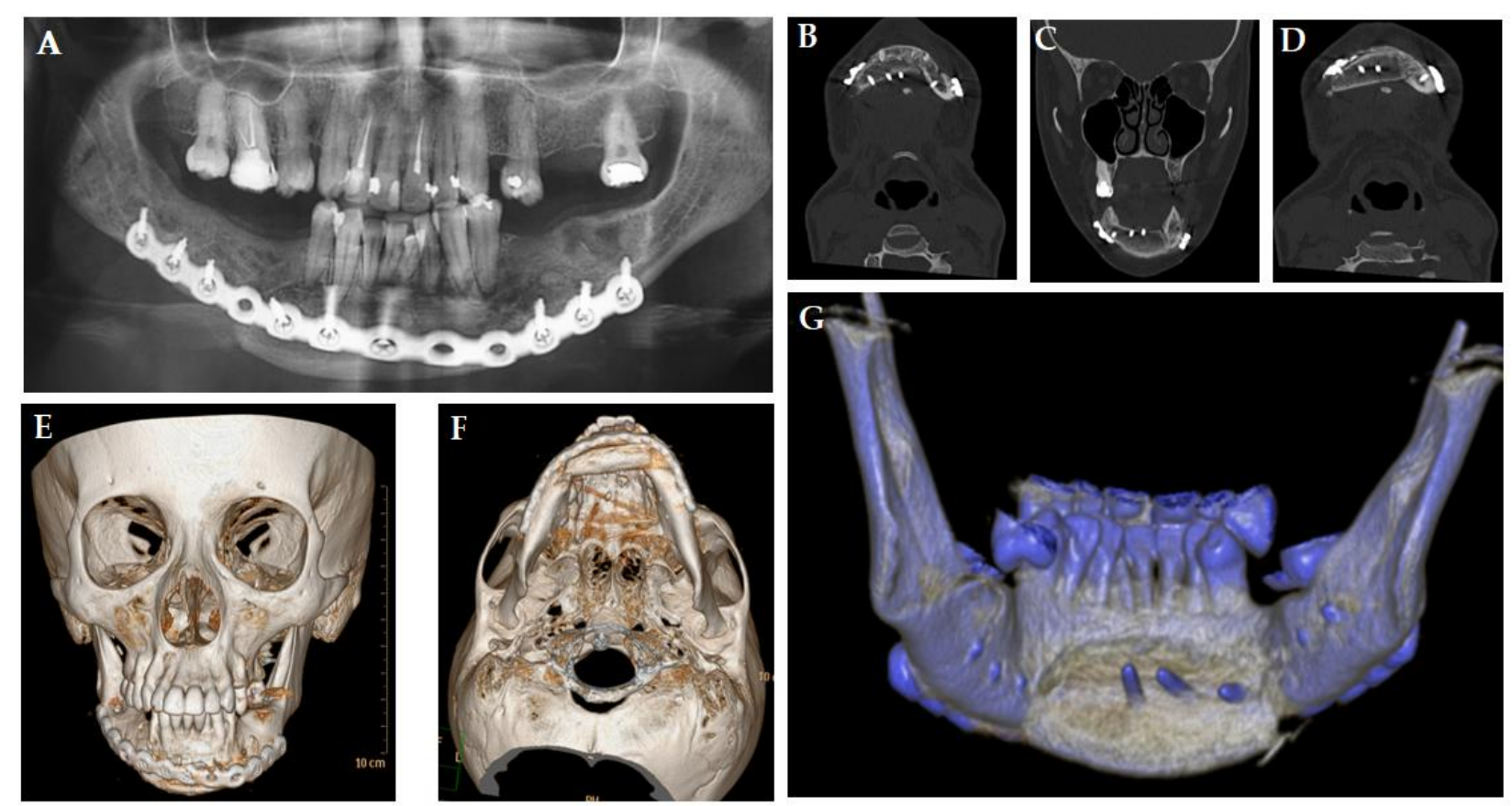

Figure 5. A. Panoramic radiograph 6 months after the operation showing indicative signs of incorporation of the graft into the recipient area. B. Coronal computed tomography of the face showing the incorporation of the graft after six months. C. and D. Axial computed tomography of the face showing the incorporation of the graft into the mandibular stumps and the alveolar segment after six months. E. and F. Threedimensional reconstruction of computed tomography of the face showing the incorporation of the graft into the mandibular stumps and the alveolar segment after six months and the mandibular contour obtained in a submentovortex view. G. Posterior view of the three-dimensional reconstruction of the face CT showing the incorporation of the graft into the mandibular stumps and the alveolar segment after six months.

\section{Discussion and Conclusion}

To contextualize the importance of the case report presented, we identified a total of six scientific articles that also sought to describe this pathology clinically (Table 1).

In a study by Alsharif et al. [7], with 127 cases of benign fibro-osseous lesions of the jaws, the FCO had an incidence of $43.30 \%$ and the group most affected was a man in the second decade of life. In the study by Santos et al. [1] with 112 cases of benign fibro-osseous lesions of the jaws, it was identified that
54 were cemento-ossifying fibroma, which corresponds to almost $50 \%$ of the samples, demonstrating that this pathology is not so rare in population.

The clinical behavior of the lesion in the case reported in the present study was asymptomatic, being unveiled after the radiographic examination requested after clinical evaluation, where a mandibular swelling was found, with bulging of the cortical bone, firm on palpation, absence of tooth mobility, with the skin and normal-looking covering mucosa, associated with facial asymmetry and without associated 
paresthesia. These clinical findings are in accordance with the description of the lesion made by Neville et al. [3], Lopes et al. [2].

The Cemento-Ossifying Fibroma (CFO) are preferentially observed in the posterior region of the mandible, mainly in the premolars and molars, although Triantafillidou et al. [4], Bist et al. [5], Castro et al. [6] have published the involvement of other structures of the craniofacial complex. This information is in accordance with the topographic location of the reported case.

Radiographically, the lesions behaved as radiolucent, unilocular, well-defined, circumscribed areas, with variable radiopacity according to the amount of calcified material produced by the tumor, and very rare, completely radiopaque FCO. Divergence and root resorption may be present, although they were not observed in the case reported. In the face of extensive lesions in the mandible, a characteristic bulging below the basilar cortex may be present $[3,8]$, which corroborates the case presented.

The present report demonstrated that the use of the free bone graft from the iliac crest for the reconstruction of the mandibular continuity defect was satisfactory, having been optimized by the use of the prototype where it was possible to measure the size of the defect and perform the modeling of the bone block necessary for this.

\section{References}

[1] Santos TS, Antunes AA, Avelar RL, Carvalho RWF, Andrade ESS. Lesões fibro-ósseas benignas dos maxilares: estudo epidemiológico de 112 casos. Revista Brasileira de Cirurgia de Cabeça e pescoço, 2007,36(4):209-211.

[2] Lopes MCA, Barros SSLV, Lima CCB, Nogueira LBLV, Rocha MMF, Moraes SS. Fibroma ossificante na mandíbula: relato de caso de patologia rara. Rev. cir. traumatol. buco-maxilofac. [online]. 2013, 13(1):77-82.

[3] Neville B, Damm D, Allen C. Patologia Oral e Maxilofacial. Editora: Elsevier. $3^{\text {a }}$ Edição. Ano: 2009.

[4] Triantafillidou K, Venetis G, Karakinaris G, Iordanidis F. Ossifying fibroma of the jaws: a clinical study of 14 cases and review of the literature. Oral Surg Oral Med Oral Pathol Oral Radiol. 2012 Aug;114(2):193-9. doi: 10.1016/j.tripleo.2011.07.033.

[5] Bist SS, Varshney S, Kumar R, Bhagat S, Gupta N. Juvenile aggressive cemento-ossifying fibroma of the sinonasal tract: case report. Ear Nose Throat J. 2011 Nov;90(11):E3-7.

[6] Castro AL, Soubhia AMP, Miyahara GI, Júnior IRG, Kawata LT. Fibroma cemento-ossificante central: relato de caso. Revista Odonto, 2007, 15(29):102106.

[7] Alsharif MJ, Sun ZJ, Chen XM, Wang SP, Zhao YF. Benign fibro-osseous lesions of the jaws: a study of 127 Chinese patients and review of the literature. Int J Surg Pathol. 2009 Apr;17(2):122-34. doi: $10.1177 / 1066896908318744$. 
[8] Akcam T, Altug HA, Karakoc O, Sencimen M, Ozkan A, Bayar GR, Gunhan O. Synchronous ossifying fibromas of the jaws: a review. Oral Surg Oral Med Oral Pathol Oral Radiol. 2012 Nov;114(5 Suppl):S120-5. doi: 10.1016/j.oooo.2011.08.007.

Conflict of interest: The author declares no conflicts of interest.

Acknowledgements: None.

Funding: None.

How to cite this article: Alves RL, Gusmão JNFM, Silva BFA, Bezerra RCA, Santos ES, Lopes-Filho AM. Mandibular Reconstruction with Autogenous Graft After Surgical Treatment of Cemento-Ossifying Fibroma: a Case Report and Literature Review. Brazilian Journal of Case Reports. 2021 Abr-Jun;01(2):3-14. 